\title{
Innovative Technologies and Opportunities for the Visually Challenged: A Case Study of Academia-Industry Collaboration in Gujarat
}

\author{
${ }^{1}$ Parvathi K. Iyer, ${ }^{2}$ Kishor Jose \\ ${ }^{I}$ Assistant ProfessorCentre for Studies in Science, Technology and Innovation Policy, \\ Central University of Gujarat \\ ${ }^{2}$ Assistant ProfessorSchool of International Studies, Central University of Gujarat
}

\begin{abstract}
The present paper examines the dynamics of academia-industry collaboration in the Indian context in relation to the development of innovative technologies for visually challenged persons. Through a detailed description of the history and dynamics of a collaborative innovative effort between the Central University of Gujarat and a Baroda-based firm, to produce an instrument, the Visionmeter, the paper discusses how the collaboration is particularly significant since the instrument facilitates the entry and employment of visuallychallenged persons into fields like quality control and quality formulation, fields that were hitherto inaccessible to them. The case study is also noteworthy since it offers an alternative and possibly viable model of indigenous innovation for the empowerment of visually challenged persons in the absence of adequate government subsidies and funding for their entry into 'wet' laboratory sciences in India.
\end{abstract}

Keywords-Innovation, Visually challenged, Collaboration, Academia-Industry, Quality

\section{Introduction}

The present paper seeks to examine the dynamics of academia-industry collaboration in the Indian context in relation to the development of innovative technologies for visually challenged persons. Policy-wise, the emphasis on a model of charity rather than a model of social empowerment, has translated in terms of state apathy and minimal thrust on funding in relation to higher education and related employment opportunities for these individuals. Given this situation, the enrollment of these individuals into Science related streams and their employment in these fields, particularly the 'wet' laboratory sciences, has been typically miniscule and in certain cases, virtually non-existent. The present case study, involving a collaborative innovative effort between the Central University of Gujarat and a Baroda-based firm, to produce an instrument, the Visionmeter, is particularly significant since the instrument facilitates the entry and employment of visually-challenged persons into fields like quality control and quality formulation, fields that were hitherto inaccessible to them. The present case study is also noteworthy since it offers an alternative and possibly viable model of indigenous innovation for the empowerment of visually challenged persons, in the absence of adequate government subsidies and funding for their entry into 'wet' laboratory sciences.

The paper has been structured in the following manner. The paper begins with a brief profile of visually disabled persons in the Indian context, in addition to the policy related challenges for their empowerment. It then attempts to examine the present case study through a synthesis of perspectives obtained from the larger corpus of Science, Technology and Society (STS) studies and Sociology of Health. The following section provides a brief description of the methodology deployed for the present paper. This is followed by a detailed examination of the 'Visionmeter' project. The subsequent section discusses the significance of the collaborative effort between the Central University of Gujarat and the Baroda-based firm, Analab, in the context of empowerment of visually challenged persons and their entry into the laboratory sciences and related professions and arenas in the public and private sectors in India. The last section outlines the concluding remarks of the paper.

\section{Contextualizing Disability Management In India}

Disability is a term, often difficult to define and operationalize, due to ideological aspects, cultural settings and varied use. Its generic feature, however, is a person's difficulty in performing a particular task or activity due to an underlying physical or mental disorder. (Albrecht and Verbrugge 2000: 293). The disabled constitute around 1.85 crore persons of the total population in India. Out of every one lakh persons, around 269 persons are found to be visually disabled. The rate of visual disabilities among rural persons has also been found to be considerably higher than among urban persons. Regarding the age for onset of visual disability, it manifests itself during the early years of a person's life apart from old age. As far as the actualization of the $86^{\text {th }}$ Constitutional Amendment and Section 26 of the PWD Act, in terms of the trickling down of its benefits to visually challenged persons is concerned, aspects such as the fitment of aids and appliances for school going 
children, the streamlining of early intervention and school readiness programmes for them, access to vocational training for adolescents and systematic planning, provision of funds and outlay for delivery of services required by them, still remains to be carried out. (Sandhu 2004: 39-40). Such a dismal scenario is a crucial pointer to the fact that the pursuit of higher education, the linkage of vocational training with industry and business enterprises and their entry into the Sciences stream, still remain major policy challenges for the government. It is in this context that the present case study assumes importance.

\section{Theorizing About Disability: Perspectives From The Social Sciences}

The present paper deploys perspectives from the domain of Science, Technology and Society Studies (STSS), more specifically from the corpus of Innovation related literature, in addition to perspectives from Sociology of Health, in order to examine the nature of academia-industry collaboration in relation to technological innovation for the visually challenged.

Sociology of Health related perspectives on disability have tried to articulate its definition and origin from a multiplicity of standpoints and models, which include, historical and traditional or charity model, modernist, statistical, medical, and social and human rights related approaches ( Albrecht et al 2000). At present, we see a theoretical attempt to blend or synthesize the insights of the medical, human rights and social models of disability. Such a synthesis emphasizes on the empowerment and agential capabilities of disabled persons in terms of mobility, access to higher education and employability, rather than as the passive recipients of the state's charity or philanthropy.

From the perspective of Innovation studies, according to Schumpeter's classification, innovation includes new products, new processes, ways to penetrate new markets, new sources of supply and new ways to organize business. Innovations may also be classified into radical and incremental innovation, according to how novel they are compared to current technology (Swedberg 1991). In terms of such classification, the 'Visionmeter' falls under the category of radical innovation, since it is the first technical instrument of its kind to facilitate the entry of blind persons into the 'wet' laboratory sciences.

Cases of academia-industry collaboration are relatively common in sectors such as pharmaceuticals, IT and Biotechnology. In these sectors, we have seen how interaction between firms and other agencies, including universities, spawn innovations at the organizational level (Upadhyay et al 2002, Joseph KJ 2009). Such interactions also take the form of university licensing activity, university-founded spin-off firms, direct industrial funding of university research, university-based consultants and exchanges of research personnel. (Etzkowitz and Webster 1995, Pavitt 1984). In this context, academia-industry collaborations in the sphere of disability studies, more particularly, visual disabilities are extremely rare and virtually non-existent in the Indian context. This is what lends the present case study its profundity and significance. In addition, we find that innovation studies in the contemporary context, serve to highlight not only issues related to process and product innovation, but recognize the importance of organizational processes and institutional arrangements during collaborations among different entities like firms and universities, as the present case study attempts to illustrate, in contributing significantly to the innovation process. The present paper is also a modest attempt in this direction.

A few contemporary innovation studies' perspectives also emphasize on the 'third mission' or the larger social relevance of universities, in addition to their traditional activities of teaching and research. In this sense, the paper also attempts to understand the present innovative collaborative effort within the framework of the 'developmental university' rather than the 'entrepreneurial university', in terms of the academic institution's commitment to the development of the society of which it is a part and the formation of linkages with firms to forward such objectives, in addition to the generation of new knowledge and its application (Joseph, KJ 2009).

\section{Methodological Concerns: Tools And Techniques Of Data Collection}

As far as the tools and techniques of data collection were concerned, the present study deployed primary as well as secondary sources of data. Secondary sources included government and other reports and archival material related to disabled persons, journals, books and material from blogs and websites related to visually challenged persons in India. Primary sources of data collection included several in-depth interviews with the research team from the Central University of Gujarat (CUG) and the managerial, R\&D and production personnel from the Baroda based firm, Analab during the period from March to June 2011. In addition, documents related to the Visionmeter project, including the inventor's published journal papers on the subject were obtained from the research team at $C U G$ and Analab and perused for the study. A few interviews were also conducted with the end-users of the instrument. In addition, the authors also attended the two meetings organized by the University and the Company with regard to the launch of the product. 
Innovative Technologies And Opportunities For The Visually Challenged: A Case Study Of

\section{Development of the 'Visionmeter'}

\section{History And Dynamics Of The Collaboration:}

The present section examines the history and dynamics of academia-industry collaboration in relation to the development of the 'Visionmeter'.

The inventor developed the concept behind the 'Visionmeter' in 2004 during his tenure as a professor of Chemistry in Delhi University. The principle on the basis of which the Visionmeter was developed was that it was possible for visually challenged persons to develop appropriate expertise in areas such as volume measurements of liquid state materials such as oils, inks, soaps, pharmaceutical products, polymers etc, which would facilitate their employment in quality control and quality assurance related testing in these areas, since the electronic devices built to measure these could have the requisite safety devices and technology essential for these persons to perform the tasks competently and with ease. The instrument also essentially involved the conversion of chemical energy into electrical energy and that of electrical energy into sound energy.

The generation of the concept itself necessitated an interdisciplinary approach and knowledge of several disciplines such as physics, chemistry, including pharmaceuticals and polymer science, electronics and material sciences. Chemistry related inputs were required since the instrument was eventually to be used for quality control and testing, including the characterization and purity checking of materials. In order to facilitate the versatility of the instrument for characterization of different materials, inputs from pharmaceutical and polymer sciences were also useful. Physics related inputs were essential since the one of the principles of the instrument was to generate sound for a particular figure or frequency. Electronics was useful in this regard for sensor and signal related tasks. Knowledge of material sciences was important since the type of material used for the instrument, in terms of acoustic and non-acoustic, was also significant for transmission of the soundbased signal. It therefore required an extended perusal and examination of available literature, the fragmenting of the problem into appropriate steps and also the integration of the above-mentioned inputs and knowledge from these different disciplines.

The inventor relocated to the Central University of Gujarat in 2009 as Dean of the School of Chemical Sciences. In between, he sought the assistance of government bodies like the Department of Science and Technology (DST), Government of India, for funds to further his work on the project, but these efforts met with very little success during this critical phase. In 2009, however, with his shift to the Central University of Gujarat, Rs Six lakh worth of funding was sanctioned to set up the laboratory, initiate related infrastructural development and quicken the pace of the work. The MOU and patent licensing agreement with Analab was signed on December 9, 2010, after extensive discussions and assurance that the company possessed the requisite technological competence to develop the instrument. The company sought and received the exclusive rights to manufacture the instrument. Royalty payments were fixed at around five percent. The period of license was fixed at two years and the agreement explicitly specified that the design of the instrument would not be modified without the prior permission of the inventor.

Analab, an ISO 9001-certified company, is a manufacturer of scientific instruments. Though its tie-up with the multinational company, Thermofissure, in the initial period of its inception, and now independently, the firm has been engaged in providing analytical and scientific equipments to various chemical, pharmaceutical, agrochemical and petrochemical chemical firms, in addition to academic research institutions and defence research laboratories in the country. The head of the company, a chemical engineer by training and employed for a few years in a multinational company, Thermofissure, had prior experience of working with related technology though not in the area of disability studies. The R\&D team possessed competence in areas like mechanical engineering, electronics and alignment engineering. For Braille related inputs, the firm relied on inputs from instructors of visually challenged persons. The company did not possess any previous history of collaboration with academic institutions.

\section{Discussion}

Knowledge production involving collaborative efforts between academia and industry often does not take off due to divergence in the objectives of the two agents, namely the papyrocentricnature of academic research and the short-term vision and instrumental nature of industrial research. In the case of the Visionmeter, however, the concerned parties completed the project within a period of ten months due to the recognition of the potential worth of the final product in terms of profit as well as social relevance. Another strategy, which facilitated the quick completion of the project, was the clear and explicit fragmentation of the task at hand into simpler sub-tasks, with elaborate discussions during each stage. In addition to factors such as adequate technical expertise; the ability to communicate codified and tacit knowledge spanning a number of disciplines and integrate the inputs obtained from different specializations and work within an interdisciplinary area; the risks associated with the illicit spillover of technology were also considerable in the present context, since if the concept is revealed during the course of the collaboration and the tie-up does not fructify, it may be copied through reverse engineering and reproduced elsewhere. However, inspite of the risks associated with such ventures, it is interesting to note that no prior non-disclosure or confidentiality clause was signed in relation to 
Innovative Technologies And Opportunities For The Visually Challenged: A Case Study Of

maintenance of secrecy, highlighting that during the innovation process, informal aspects like the degree of trust between the concerned parties play an important role in the success of the collaborative effort.

The firm, subsequent to discussions on each sub-task during the different stages of the project, carried out experiments. Once the experiments were conducted, the protocols developed in the firm went through a process of verification by the academic team in the University. The project took nine months from conception to completion. Elaborate time lines were drawn for each sub-stage and a detailed implementation plan was drawn. The first two months were spent in acquiring conceptual clarity through intensive discussions, which involved both the team members from the University and the Firm. The third month was spent in finalizing details related to the hardware deployed in the instrument. During the next stage, the loading system for the sample was finalized. The alignment part of the instrument, in terms the dimensions, liquid sample loading, and outlet and pressure control was carried out in the next stage. The next stage involved the use of appropriate software for the device. The last stage involved the alignment of the software system with the sound system and the electronic part of the equipment, particularly the operation of the instrument through Braille.

The inputs of the end users, namely visually disabled persons were also sought, during the course of the project, in aspects such as the process of operation of the instrument, the process by which the sample liquid is transferred, the operation of the instrument through Braille, particularly the operating nodes, the mechanism for washing of the instrument and checking the system. These inputs contributed significantly towards improving the workability of the device and making it safe and effective for use by visually challenged persons. Once the instrument was developed, these inputs were sought once more, particularly from visually challenged persons and their instructors located at a School for the Blind in Vastrapur, Ahmedabad. Such interaction helped in terms of providing inputs related to the ability to discern different colours and incorporating the additional feature of optical density in the instrument. Thus we find that in the context of the Visionmeter, the interaction with end users has also facilitated the improvements in the existing design and contributed effectively to the innovation process.

After the development of the instrument, the government agencies, including the Technology Transfer Division, Department of Science and Technology, Government of India, have evinced considerable interest in launching the instrument and facilitating its promotion among educational institutions and civil society organizations working for the visually challenged persons. There are bottlenecks, however, in terms of costs, as the instrument is priced at nearly Rs Ten lakh per unit.

\section{Conclusion}

The development of the Visionmeter marks a significant landmark in the efforts to encourage the empowerment of the visually challenged persons in India, namely due to its importance and potential for contribution in the sphere of science education and related skilled employment, not only in government institutions but also in the private sector. As far as the development of the Visionmeter is concerned, the success of the project and the subsequent interest evinced by the government agencies clearly demonstrates the potential for a Triple Helix Model of Innovation in the context of generating favorable policies and promotion of the instrument by governmental agencies in educational institutions for the Blind, incentives to the inventors and manufacturers of such instruments, the promotion of such instruments in various relevant industries in order to train and employ visually challenged persons in their organizations and increased provision of funds to encourage innovative research in related areas. As mentioned earlier, in the absence of government support for such ventures, the model of collaboration documented in the case study also offers an alternative and viable model of indigenous innovation in an area with tremendous research and application potential.

\section{Acknowledgement}

The authors would like to express their gratitude to Prof. Mansingh and his research team at the Central University of Gujarat and the proprietors of the Baroda-based firm, Analab, for the detailed interviews, discussions and the material in connection with the Visionmeterproject.

\section{References}

\section{Journal Papers}

[1]. Pavitt, Keith. 1984. Patterns of Technical Change: Towards a Taxonomy and a Theory. Research Policy. 1998. 13:343-74.

Books

[2]. Fagenberg, Jan, Mowery, David and Nelson, Richard. The Oxford Handbook of Innovation Studies (United Kingdom, Oxford University Press, 2005)

[3]. Swedberg, R. Joseph Schumpeter: His Life and Work (Cambridge, Polity Press, UK, 1991)

[4]. Albrecht, Gary, Fitzpatrick, Ray and Srimshaw, Susan C. Handbook of Social Studies in Health and Medicine( Sage Publications, 2003)

[5]. Lundvall, Bengte-Ake, Joseph KJ, Chaminade, Cristina and Vang, Jan (eds). Handbook of Innovation Systems and Developing Countries (UK, Edward Elgar, 2009)

\section{Chapters in Books}


[6]. Joseph, KJ.Sectoral Innovation Systems in Developing Countries: The Case of ICT in India, inLundvall, Bengte-Ake, Joseph KJ, Chaminade, Cristina and Vang, Jan. (Eds) Handbook of Innovation Systems and Developing Countries (UK, Edward Elgar, 2009)

[7]. Etzkowitz, Henry and Webster, Andrews, Science as Intellectual Property, in Jassanoff, Sheila, Markle, Gerald, Peterson, James, C and Pinch, Trevor (Eds) Handbook of Science and Technology Studies (Sage Publications, 2005)

[8]. Sandhu, R. Introduction, in Mohapatra, CS (Ed) Disability Management.: Challenges and Commitments.Secunderabad, National Institution for the Mentally Handicapped, 2004)

Reports

[9]. Upadhyay, $\mathrm{V}$ et al.Socio-Economic Impact of the role of In-House R\&D in Indian Industry: A Case Study of the Pharmaceutical \&Tyre Sectors (Department of Science and Technology (DST) Report, Government of India, 2002) 